\title{
Influence of the size of walnut shell particulates on mechanical properties of epoxy-based composites
}

DOI : 10.36909/jer.ICIPPSD.15541

\author{
Satish Kumar Shejkar*, Basant Agrawal* and Alok Agrawal** \\ *Mechanical Engineering Department, Shri Govindram Seksaria Institute of Technology and \\ Science, Indore, India. \\ **Mechanical Engineering Department, Sagar Institute of Research \& Technology-Excellence, \\ Bhopal, India. \\ *Email: shejusarang25@gmail.com; Corresponding Author.
}

\begin{abstract}
In the present work, a new class of polymer composite is developed using walnut shell powder (WSP) as particulate filler in the epoxy matrix. Three different sizes of WSP are used for preparing three different sets of composites. The particle size selected is 50-micron, 75-micron, and 100-micron. In each set of composites with different particle size, four compositions i.e., 5 wt. $\%, 10$ wt. $\%, 15$ wt. $\%$ and $20 \mathrm{wt}$. \% of the WSP is fabricated. All prepared composites have undergone testing to study the behavior of the material under mechanical loading. The different mechanical tests performed are the tensile test, flexural test, compressive test and hardness test. From the experimentation, the inclusion of WSP appreciably alters the different mechanical properties of epoxy. With the increase in the content of filler, an appreciable increase in the value of hardness and compressive strength is observed. Though, it has been seen that the tensile strength and flexural strength of the material is compromised slightly when the content of WSP increases beyond a certain limit. Further, it is observed that composites fabricated with smaller size particles give improved mechanical properties as compared to their counterparts.
\end{abstract}

Keywords: Epoxy; Green Composites; Mechanical properties; Walnut shell Particles. 


\section{INTRODUCTION}

In recent times, unique combinations of material properties are the prime requirement of the modern industries of the world that cannot be fulfilled by any of the traditional materials. That's why material engineers and scientists have shifted their interest towards composite materials. Composite materials are composed of two or more different materials possessing properties higher than those of the individual constituents (Erbayrak and Erbayrak, 2020). They comprise two phases i.e., matrix phase and reinforcement. Based on the matrix phase, composites are classified as the metal matrix, ceramic matrix, and polymer matrix composites. There are several advantages of polymers over other materials due to their exceptional combination of hydrogen and carbon atoms (Zabba and Ismail, 2018). It has been seen that polymer alone does not satisfy the required properties in most of the applications. Hence, reinforcing polymer with a suitable filler is required to alter its properties. Synthetic as well as natural fibre/fillers both are in use as reinforcement with the polymeric matrix. The usage of synthetic fibres is reducing apart from its various advantage because of their high processing cost. They are also non-biodegradable and are harmful to the environment. Hence, reinforcement of fibres and particles derived from nature is the need of an hour. Natural fibres are of interest for many years as reinforcement. According to Manickam et al. (2015) mechanical and wear behavior of the vinyl ester polymer improves as the content of Roselle fibre increases. Against that, Zardari (2020) found a decrement in the value of compressive strength of compressed earth blocks when jute fibres are added. He also found that deflection of the material reduces with the addition of jute fibre although the modulus of rupture slightly increases with the increase in the content of jute fibre. Olufemi et al. (2020) found an increment in the value of compressive strength when hair fibres are added along with cement in compacted laterite soil and found that the developed material has immense potential to be used for road construction material.

Bio-waste particulates obtained from the shell of different edible nuts have great potential to be used as fillers. Such materials are suitable as they are light in weight. Apart from that, most of them are hard, tough and possess good thermal properties. The most important property is that they are biodegradable. A lot of work has been reported in the past taking bio-waste particulates obtained from the shell of different edible nuts as filler in the polymeric matrix. In this note, Raju and Kumarappa (2011) used peanut shell particles with epoxy resin to develop bio-based composites and evaluated the mechanical properties. From the analysis, they found that 
composites with low filler content provide a better result as compared to composites with high filler content. Besides, an important finding of their work is that smaller size particles $(0.5 \mathrm{~mm})$ give superior results as compared to larger size particles (1mm). Sallal (2014) used a polyurethane matrix and prepared a composite by varying the content of coconut shell powder. They found that the mechanical properties of the material improve significantly with the addition of micro-particulates coconut shell powder. Shehu et al. (2014) investigated the effect of incorporation of palm kernel shell particles on polyester-based composites. They reported achieving better interaction between the two phases when the size of the particles is 300-micron. Apart from the usage of palm kernel shell as filler in composites, Oladosu et al. (2021) investigated the combustion of palm kernel shell with coconut shell in grate furnace. From the analysis, they found that palm kernel shell burns effectively with coconut husk and creates a significant effect on temperature and emission characteristics of the biofuel. Kumar et al. (2017) used epoxy with coconut shell powder and evaluated the mechanical properties of the developed material. Alsaadi et al. (2018) took a pistachio shell in the form of the particle in the polyester matrix and evaluated the mechanical behaviour of the material and found that tensile strength increases when a small amount of filler material is added and decreases after that. Seth et al. (2018) used doum palm shell particles as a filler material with the polypropylene matrix. They took two different size particles (150-micron and 300-micron) and studied the tensile and flexural properties of the material as a function of filler and filler size. They found a similar trend with both particle sizes, but enhanced properties are obtained with smaller size filler.

Nitin and Singh (2013) were the first to use the particles of the walnut shell as a filler in the composite. They studied the physical and mechanical properties of the material and found that the inclusion of walnut shell particles in epoxy resin increases the specific properties of the material. Ahalwatet al. (2018) explored the different properties of polyester composites with WSP particles. Salasinka et al. (2018) conducted various experiments using epoxy and walnut shell particulates and thereby concluded that the stiffness and hardness of the fabricated material are improved. The mechanical property of walnut shell powder as filler in polypropylene matrix is evaluated by Moustafa et al. (2020). In their work, they observed that the tensile and flexural strength of the material decreases with an increase in filler content. Though, improvement in hardness with filler content is observed in their work. It has been seen that, among the various edible shell powder used as filler material in polymeric resin, the walnut shell has been a less 
explored area. Also, the effect of the size of particles of walnut shell is nowhere reported. With this, the present work comprises of developing composites with walnut shell particles of different size as filler material in epoxy resin. The variation in size and content of particles on various mechanical properties of the developed composite is under investigation.

\section{MATERIALS AND METHOD}

Lapox L-12 epoxy resin is selected as matrix material in the present investigation. Epoxy is selected because various physical and mechanical properties of epoxy are superior in comparison with various other polymers. It has excellent thermal stability and high degradation temperature. Epoxy is used with its corresponding hardener tri-ethylene-tetramine (TETA). Epoxy with its corresponding hardener is procured from ATUL India Ltd., Gujarat, India. The filler used is the walnut shell in the form of micro-particulates. This walnut shell has a low specific gravity of around 1.3. It has a high hardness of shore D number 80. The hand lay-up technique is used for the fabrication of epoxy composites in this work. Walnut shell particles of size 50-micron, 75micron and 100-micron are used for the fabrication of composites. With each particle size, four compositions are prepared with a filler content of 5 wt. $\%, 10$ wt. $\%, 15$ wt. $\%$ and 20 wt. $\%$.

Tensile, compressive, and flexural tests are performed in the computerized Instron 3382 Universal testing machine. Tensile tests are conducted by the ASTM D638 procedure. The compressive test is performed as per ASTM D695 standard. The three-point bend test was carried out as per ASTM D2344-84 to measure the flexural strength of the composites. SHD Shore hardness test was carried out by PosiTector SHD Shore hardness Durometer as per ASTM D-2240.

\section{RESULTS}

The ultimate tensile strength of unfilled epoxy and its composites with walnut shell particulates as filler for varying content and size of particles is shown in Fig.1 (a). It is noticed that irrespective of the size of filler, the strength of the material under tensile loading increases as the filler content increases. The increment of tensile strength is limited up to $10 \mathrm{wt} \%$ filler. The tensile strength increases due to the strengthening effect of the filler as filler provide rigidity and make the material stronger. At low filler content, the wetting of filler is proper which helps to improve the load transferability and hence tensile strength increases. Once the filler content increases beyond $10 \mathrm{wt}$ \%, gradual reduction in the value of tensile strength is noticed. It is 
because excessive filler results in the agglomeration and low wetting of filler. This results in weak bonding between the two phases. Due to this inhomogeneous dispersion of filler in the matrix, stress concentration took place in certain areas and reduced the overall strength of the material.

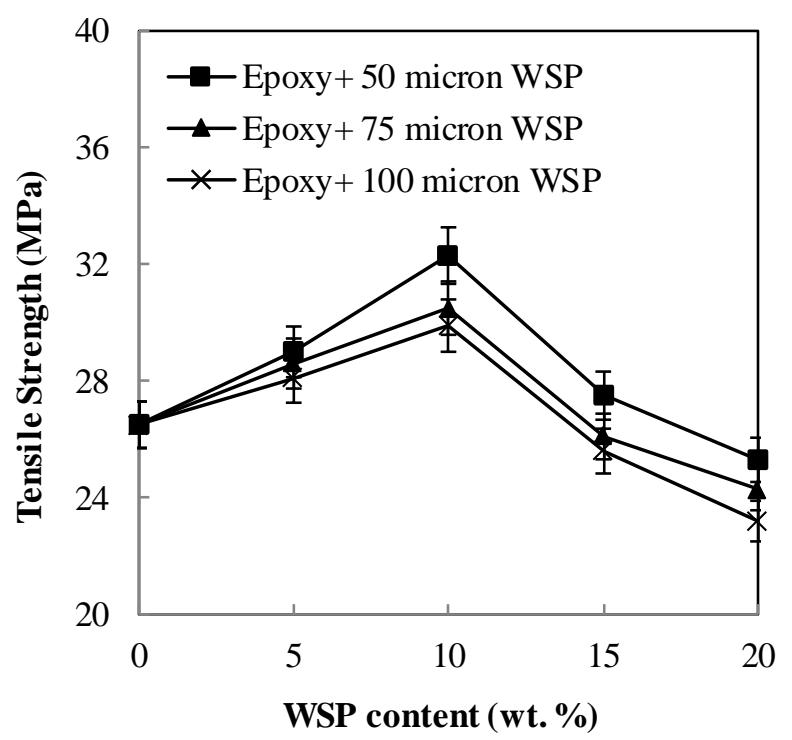

(a)

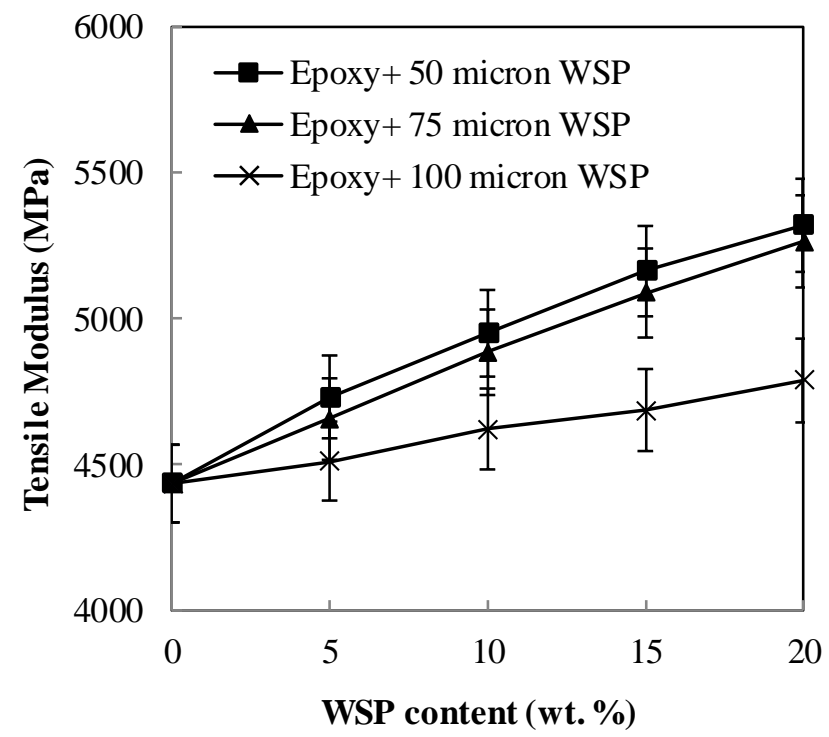

(b)

Figure 1 Tensile properties of epoxy/WSP composites: (a) ultimate tensile strength, (b) tensile modulus.

Again, it is clear from Fig.1 (a) that the size of particles also governs the tensile strength of the material. For filler content, tensile strength reduces with an increase in the size of the particles. It is mainly because the small size particle provides increased surface area for given filler content. Due to this large surface area is available to create bonding between the filler and matrix. Hence, the interaction between the two phases improved. Small size particles also had the capability of more uniform dispersion as compared to larger size particles. With improved distribution and interaction, smaller size particles provide relatively better ultimate tensile strength. Similar behavior is observed by Agrawal and Chandrakar (2019) earlier. Maximum ultimate tensile strength is obtained for a combination of epoxy with $10 \mathrm{wt}$ \% WSP filler of 50-micron size is 32.3 MPa. This is an increment of $21.88 \%$ over neat epoxy. At similar filler content, epoxy with 
75-micron and 100-micron particle size gives ultimate tensile strength of $30.5 \mathrm{MPa}$ and 29.9 MPa respectively.

Fig.1 (b) shows the value of tensile modulus for different sets of composites fabricated in the present work. It is clear from the figure that the tensile modulus of the filled epoxy is higher than the unfilled one. The increase in tensile modulus is proportional to the filler content. Also, the tensile modulus is more for smaller size filler. Hence, the maximum tensile modulus is obtained for $20 \mathrm{wt}$. \% of WSP for particle size 50-micron. For this combination, the tensile modulus is $5320 \mathrm{MPa}$ which is an increment of $19.95 \%$ over neat epoxy. With the increase in filler content, tensile modulus increases as the addition of filler provide stiffness to the material. The increase in tensile modulus is because of the high rigidity of WSP particles compared to the polymer. Again, smaller size fillers provide better dispersion of particles in epoxy resin, and this is the reason for the higher value of tensile modulus for smaller size particles.

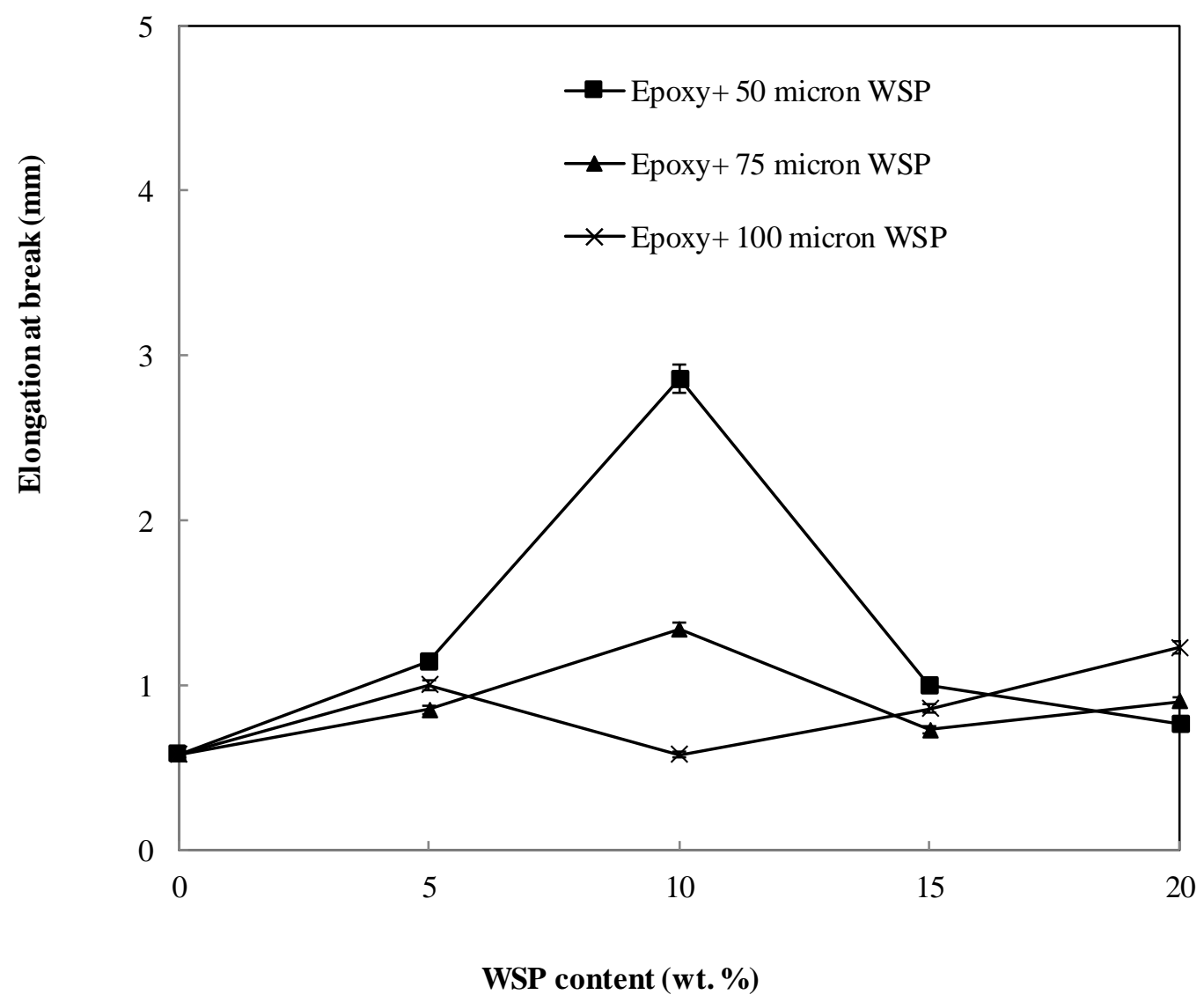

Figure 2 Elongation at break of epoxy/WSP composites 
Results for the variation of elongation at break of epoxy-WSP composite for different filler loading and particle size is shown in figure 2. Elongation at the break for neat epoxy is $0.579 \mathrm{~mm}$ which increases when a small amount of filler is added and reduces thereafter. Also, with the increase in the size of particles, elongation of break reduces for low filler content. As the filler loading increases, the elongation of material is almost the same before it breaks for all particle sizes under investigation. Maximum elongation at break is registered for the epoxy composite of 10 wt. \% WSP of 50-micron size. The extension of $2.86 \mathrm{~mm}$ occurs before the material breaks. Elongation at break shows the ductile nature of the material. Hence, it can be said that the brittle nature of epoxy changes to ductile when a limited amount of filler is added.

Fig. 3 (a) shows the changes in the flexural strength of the material for filler content and particle size. The variation in the value of the flexural strength with filler content and size of particles is like that obtained for ultimate tensile strength. Here also, the flexural strength of the material increases with filler content for a limited quantity of filler i.e. $10 \mathrm{wt}$ \% $\%$ and decreases thereafter. Also, smaller size particles show superior flexural properties in comparison to bigger size particles. The reason for such behaviour is due to the proper wetting and uniform distribution of filler when limited and small size fillers are used. Similar behaviour in flexural strength is obtained by Alsaadi et al. (2018) during their investigation on polyester composites filled with pistachio shell particles. Flexural strength of neat epoxy is measured $32.2 \mathrm{MPa}$ wich increases for $10 \mathrm{wt}$. \% filler to $48.13 \mathrm{MPa}$ for 50 -micron particle size, $42.56 \mathrm{MPa}$ for 75 -micron particle size and 39.81 MPa for 100-micron particle size. Like the tensile modulus, flexural modulus also increases with filler content as shown in Fig.3 (b). Here also, smaller size filler shows higher modulus for given filler content. Maximum flexural modulus is registered for epoxy with $20 \mathrm{wt}$. \% WSP of 50-micron particle size. The value obtained in this case is $4825 \mathrm{MPa}$ against 3543 MPa for neat epoxy. An increment of $36.18 \%$ is obtained in this case.

The variation in compressive strength of epoxy composites filled with WSP for different particle loading and particle size is presented in figure 4. It is seen that the compressive strength of the material increases as the filler loading increases. It is mainly due to the strengthening effect provided by the walnut shell particles. An increase in compressive strength is a result of the excellent ability of walnut shell particles to obstruct dislocation movement which leads to a higher strength value under compressive loading situation. 


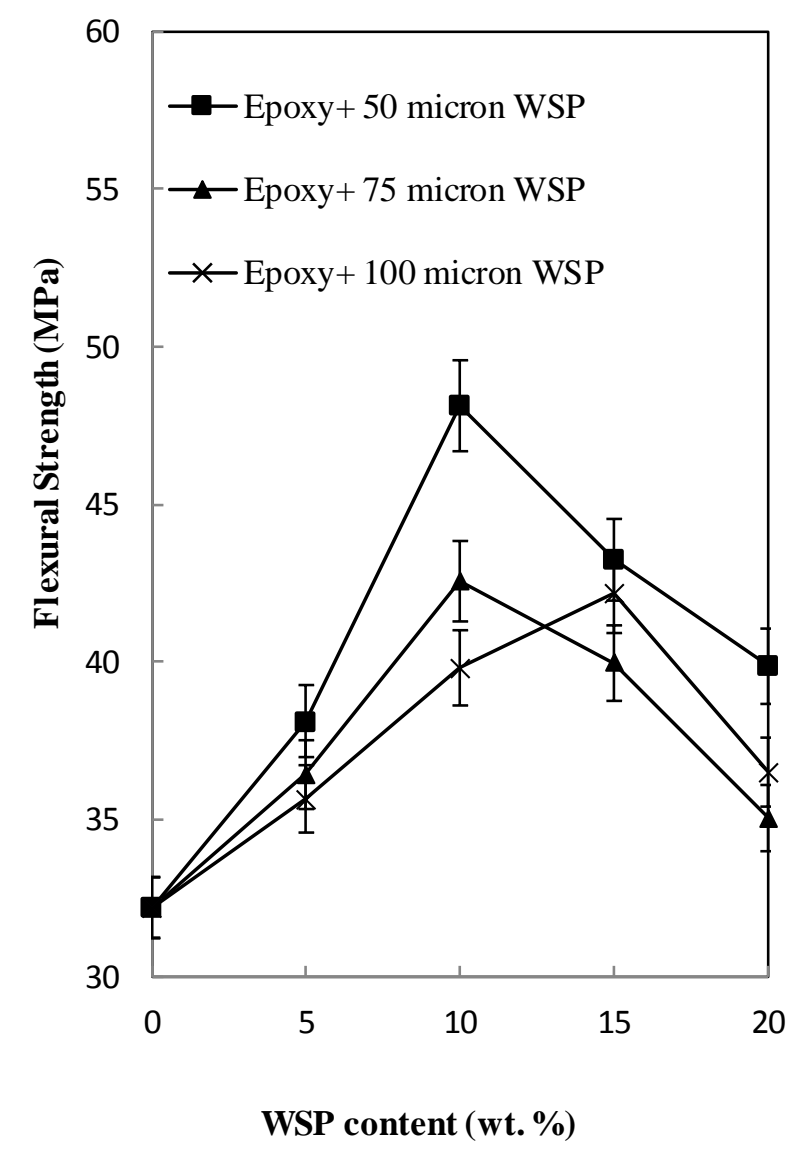

(a)

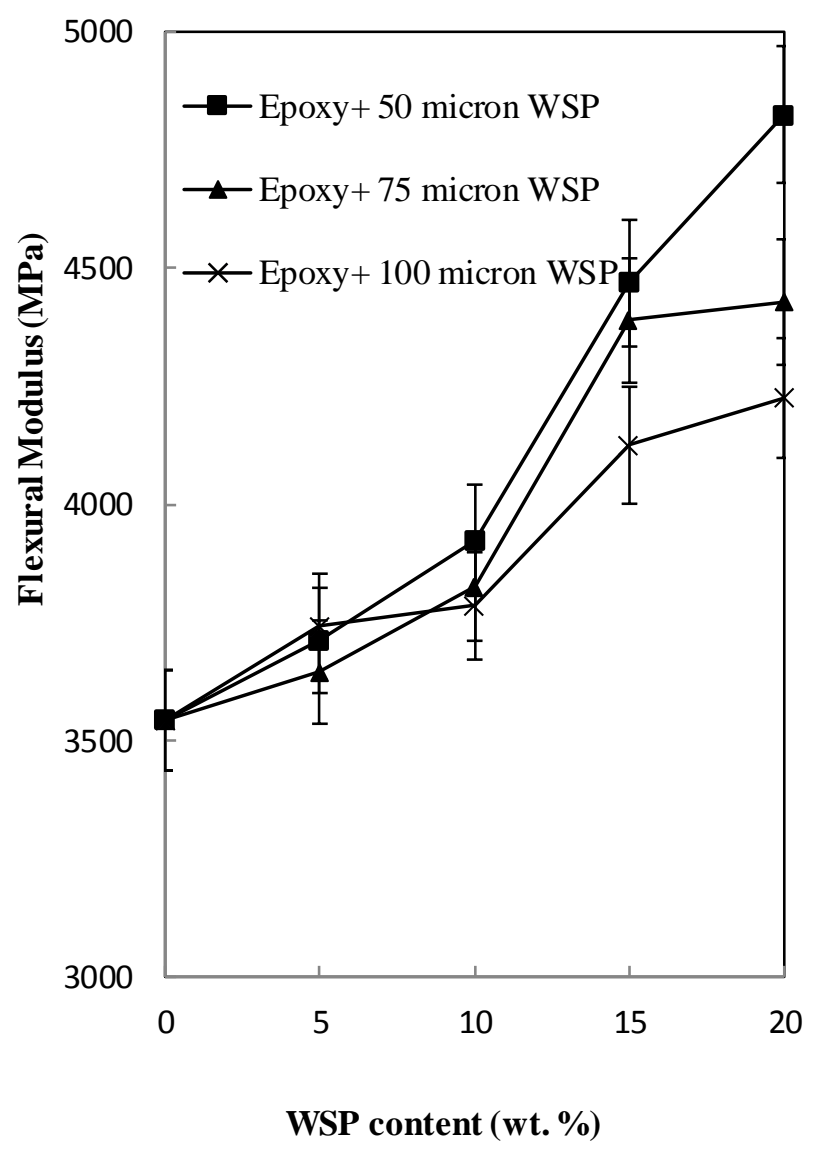

(b)

Figure 3 Flexural properties of epoxy/WSP composites: (a) flexural strength, (b) flexural modulus.

Again, it is observed that composites prepared with smaller size particles give better compressive strength value. Again, uniform distribution of smaller size particles in the epoxy matrix and less stress concentration points is the result of higher compressive strength in such composites. Maximum compressive strength of epoxy composites with 50-micron, 75-micron and 100micron particle size are 96.1 MPa, 95.2 MPa and 94.1 MPa respectively. This is an increment of $16.5 \%, 15.4 \%$ and $14 \%$ respectively over neat epoxy. 


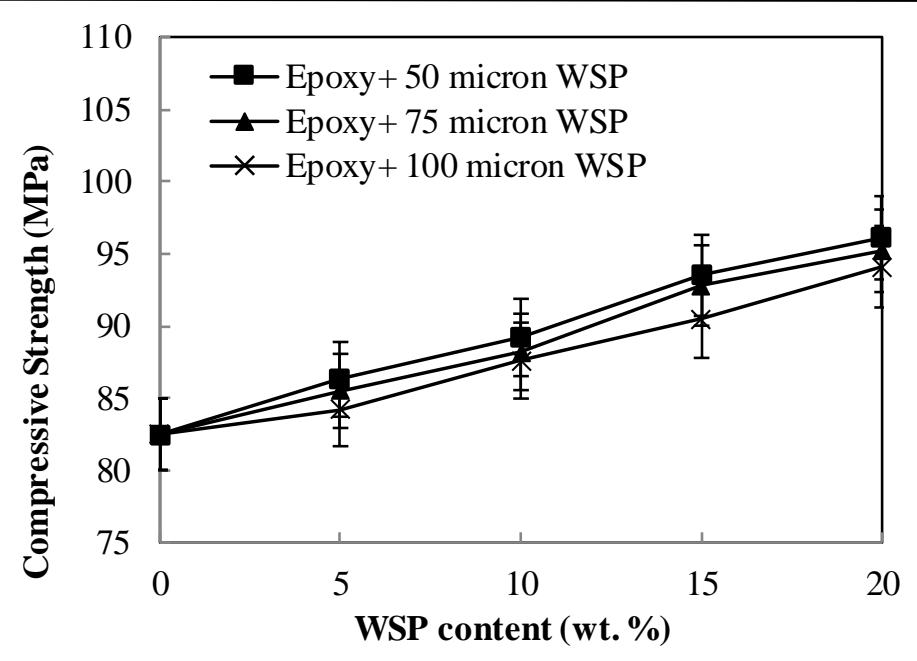

Figure 4 Compressive strength of epoxy/WSP composites

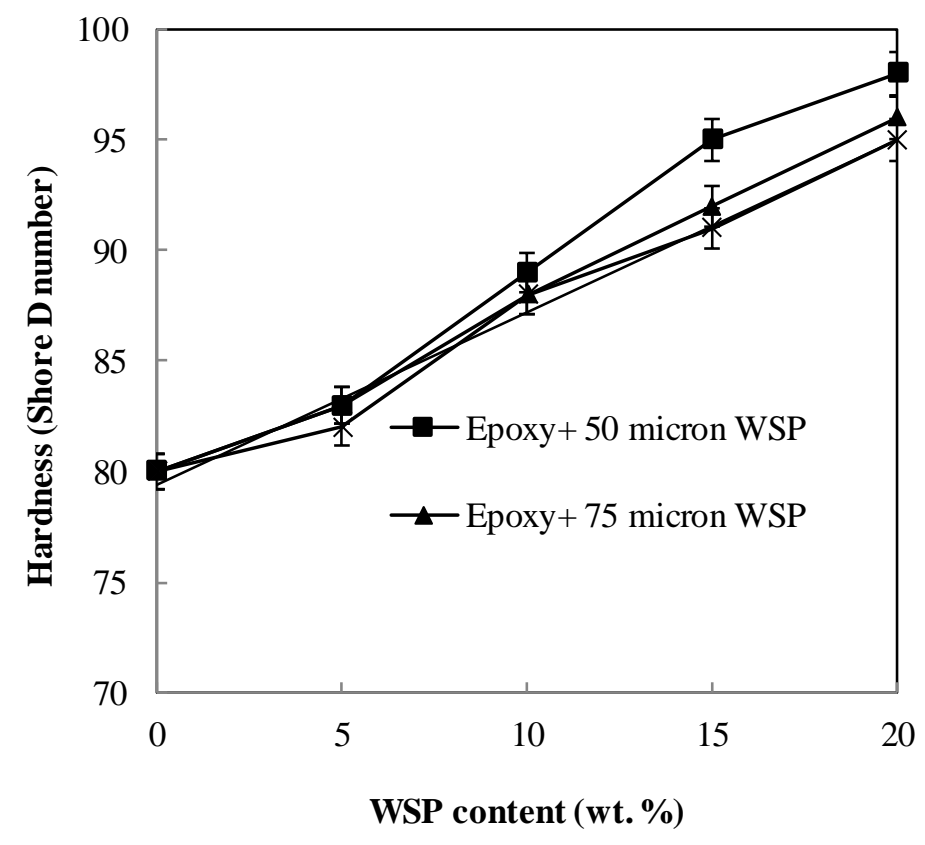

Figure 5 Hardness of epoxy/WSP composites

Figure 5 shows the variation in the value of Shore D hardness for the content of filler and the size of particles. It is clear from the figure that the inclusion of walnut shell particles increases the hardness of the epoxy irrespective of the size of the filler. The increase in hardness is primarily a function of WSP content. This can be related to the presence of particles and their ability to enhance the property of the matrix to deform plastically. The shore hardness value of neat epoxy is 80 and the maximum improvement is registered for composite filled with $20 \mathrm{wt}$ \% of WSP of mean size 50-micron. The value obtained is 98 which is an improvement of $22.5 \%$ 
over neat epoxy. It is further seen from figure 5 that the size of the filler is also a governing factor for the hardness of the composite. Hardness is more when composites are fabricated with smaller size particles.

The hardness of composites fabricated with 75-micron particle size reaches a maximum of 96 and that fabricated with the 100-micron size is 95 for filler content of $20 \mathrm{wt}$. \%. This may be related to the ability of small size particles to achieve better adhesion and distribution as compared to their counterparts.

\section{CONCLUSIONS}

From the present investigation it is concluded that irrespective of the size of filler, tensile strength increases with filler loading up to $10 \mathrm{wt}$. \%. Once the filler content increases beyond 10 wt. \%, gradual reduction in the value of tensile strength is noticed. Further, due to improved distribution and interaction, smaller size particles provide relatively better ultimate tensile strength. The tensile modulus of the filled epoxy is higher than the unfilled one. Also, the tensile modulus is more for smaller size filler. Trend obtained in flexural properties is like that obtained in the case of tensile properties. The compressive strength increases with an increase in filler loading. Maximum compressive strength is obtained for the composite of $20 \mathrm{wt}$ \% filler. Also, composite fabricated with smaller size particles have better compressive strength as compared to their counterparts. The shore hardness value of composite filled with $20 \mathrm{wt} \%$ of WSP of mean size 50-micron is 98 as compared to neat epoxy that's value comes out to be 80 . This reflects an improvement of $22.5 \%$ over neat epoxy.

\section{ACKNOWLEDGMENT}

The authors would like to express gratitude towards the Department of Science and Technology (DST), Government of India for providing the necessary facilities for composite fabrication in equipment purchased under the grant of the project titled "Design and development of polymer composite for microelectronic applications" in this line through ECR/2017/000540.

\section{REFERENCES}


Erbayrak, E. \& Erbayrak, S. (2020). Determination of the impact damage threshold point of the composite material using fuzzy-based taguchi method. Journal of Engineering Research 8(3). https://doi.org/10.36909/jer.v8i3.7992.

Zaaba, N.F. \& Ismail, H. (2018). A review on peanut shell powder reinforced polymer composites. Polymer-Plastics Technology and Engineering 58(4): 349-365. https://doi.org/10.1080/03602559.2018.1471720.

Manickam, C., Kumar, J., Athijayamani, A., \& Diwahar, N. (2015). Mechanical and wear behaviors of untreated and alkali treated roselle fiber-reinforced vinyl ester composite. Journal of Engineering Research 3(3): 97-109. DOI 10.7603/s40632-015-00254.

Zardari, M. A. (2020). Structural behaviour of large size compressed earth blocks stabilized with jute fiber. Journal of Engineering Research 8(2).

Oluremi, J. R., Adedokun, S. I., Yohanna, P., Fadiran, D. A., \& Azeez, I. O. (2020). Evaluation of Compacted Laterite Soil Admixed with Cement and Hair Fibres as Road Construction Material. Journal of Engineering Research 8(1). DOI: https://doi.org/10.36909/jer.v8i1.4966.

Raju, G.U. \& Kumarappa, S. (2011). Experimental study on mechanical properties of groundnut shell particle reinforced epoxy composites. Journal of Reinforced Plastics and Composites 30(12): 1029-1037. https://doi.org/10.1177/0731684411410761.

Sallal, H. 2014. Effect of the addition Coconut shell powder on properties of polyurethane matrix composite. Al-Nahrain Journal for Engineering Sciences 17(2): 203-210. https://nahje.com/index.php/main/article/view/223.

Shehu, U., Aponbiede, O., Ause, T. \& Obiodunukwe, E.F. (2014). Effect of particle size on the properties of polyester/palm kernel shell (PKS) particulate composites. Journal of Materials and Environmental Science 5(2): 366-373.

Oladosu, K., Mustapha, A., Durowoju, M., \& Ogunsanya, O. (2021). Performance evaluation of combustion of palm kernel shell and coconut husk blend in a pilot scale grate furnace. Journal of Engineering Research 9(1). https://doi.org/10.36909/jer.v9i1.8603. 
Vinod Kumar, T., Chandrasekaran, M. \& Santhanam, V. (2017). Characteristics analysis of coconut shell husk reinforced polymer composites. ARPN Journal of Engineering and Applied Sciences 12(8): 2401-2406.

Alsaadi, Md., Erklig, A \& khaleefah, K.A. (2018). Effect of pistachio shell particle content on the mechanical properties of polymer composite. Arabian Journal for Science and Engineering 43(9): 4689-4696. https://doi.org/10.1007/s13369-018-3073-x.

Seth, S.A., Aji, I.S. \& Tokan, A. (2018). Effects of particle size and loading on tensile and flexural properties of polypropylene reinforced doum palm shell particles composites. American Scientific Research Journal for Engineering, Technology and Sciences 44(1): 231-239.

Nitin, S. \& Singh, V.K. (2013). Mechanical behavior of walnut reinforced composite. Journal of Materials and Environmental Science 4(2): 233-238.

Ahlawat, V., Kajal, S. \& Parinam, A. (2018). Experimental analysis of tensile, flexural and tribological properties of walnut shell powder/polyester composites. EuroMediterranean Journal for Environmental Integration 4(1): 1-9. https://doi.org/10.1007/s41207-018-0085-6.

Salasinska, K., Barczewski, M., Gorny, R. \& Klozinski, A. (2018). Evaluation of highly filled epoxy composites modified with walnut shell waste filler. Polymer Bulletin 75: 25112528. https://doi.org/10.1007/s00289-017-2163-3.

Moustafa, N.M., Abdulkareem, K. Mohammed, Al-Ameen, E.S., Ogaili, A.A.F. \& Mustafa Al-Sabbagh, M.N. (2020). Mechanical and tribological properties of walnut/polypropylene natural composites. Journal of Mechanical Engineering Research and Developments 43(4): 372-380.

Agrawal, A. \& Chandrakar, S. (2020). Influence of particulate surface treatment on physical, mechanical, thermal, and dielectric behaviour of epoxy/hexagonal boron nitride composites. Polymer Composites 41(4): 1574-1583. https://doi.org/10.1002/pc.25479. 